\title{
Trivialising the Issue
}

I read with great frustration recently in a major Australian newspaper an article entitled 'Learn to Knit and Cast off Smoking', which reported on the establishment of knitting classes in Sydney and Melbourne to help smokers 'kick the habit'. The classes have been started by a former smoker who found knitting helped her quit smoking and are supported by official health bodies involved in smoking cessation.

My question is, where is the evidence?

Smoking is not a habit, but a behaviour driven by the brain to administer nicotine into the bloodstream, ultimately for use in noradrenergic and dopaminergic pathways (nicotine dependence; Piasecki \& Newhouse, 2000). Nicotine dependence is a chronic disease which requires ongoing medical treatment, as do all other medical illnesses and medical disorders (US Department of Health and Human Services, 2000). Where is the medical process of assessing nicotine dependence, tailoring treatment (smokers are not a homogenous group), treatment monitoring and education into relapse prevention when it comes to knitting? It is well documented that treatment which is tailored to the person's dependence level and which is intensive (dose related) results in better long-term abstinence rates (Steinberg, Foulds, Richardson, Burke, \& Shah, 2006; Mclure \& Swan, 2006). The long-term efficacy of medications to treat nicotine dependence (combination NRT, buproprion and nortriptyline) is also well documented (US Department of Health and Human Services, 2000). Where are the clinical trials for knitting? Imagine if we told our patients with heart disease to 'go and knit and your heart disease will go away'. What standard of clinical practice would this be? The article reports that knitting provides a good social network for support for quitting. Similarly, there is no scientific evidence that enlisting support from others improves long-term outcomes.

When is the disease of nicotine dependence going to be taken seriously? Are we not setting smokers up to 'fail' yet again? Are we not causing them 'more harm'? As long as the disease of nicotine dependence is trivialised by the media and official health bodies, smokers will continue to have no access to evidence-based medical treatment of nicotine dependence. This is a violation of their medical rights and sadly, the morbidity and mortality will continue.

\section{Donna Harrison \\ Clinical Nurse Consultant Nicotine Dependence}

\section{References}

Piasecki, M., \& Newhouse, P. (2000). Nicotine in psychiatry: Psychopathology and emerging therapeutics. Washington, DC: American Psychiatric Press.

US Department of Health and Human Services. (2000). Reducing tobacco use: A report of the US Surgeon General. Atlanta, GA: Author.

Steinberg, B., Foulds, J., Richardson, D., Burke, M., \& Shah, P. (2006). Pharmacotherapy and smoking cessation at a tobacco dependence clinic. Preventative Medicine, 42, 114-119.

Mclure, J., \& Swan, E. (2006). Tailoring nicotine replacement therapy: Rationale and potential approaches. CNS Drugs, 20(4), 281-291.

US Department of Health and Human Services. (2000). Treating tobacco use and dependence: Clinical practice guideline. Rockville, MA: Author. 